\title{
Dawn of autonomous vehicles: review and challenges ahead
}

\author{
Nuno Sousa $^{13}$, João Coutinho-Rodrigues ${ }^{14}$, Arminda Almeida ${ }^{25}$, Eduardo Natividade-Jesus ${ }^{16}$ \\ ${ }^{1}$ Researcher, Institute for Systems Engineering and Computers of Coimbra, Coimbra, Portugal. \\ ${ }^{2}$ Researcher, CITTA - Research Centre for Territory, Transports and Environment, Coimbra, Portugal \\ ${ }^{3}$ Assistant Professor (invited), Department of Sciences and Technologies, Open University, Lisbon, Portugal. MSc, PhD. \\ E-mail: nsousa@uab.pt,nunosousa@dec.uc.pt \\ ${ }^{4}$ Full Professor, Department of Civil Engineering, University of Coimbra, Portugal. CEng, MSc, PhD, Aggr. E-mail: \\ coutinho@dec.uc.pt \\ ${ }^{5}$ Assistant Professor, Department of Civil Engineering, University of Coimbra, Portugal. CEng, MSc, PhD. E-mail: \\ arminda@dec.uc.pt \\ ${ }^{6}$ Assistant Professor, Department of Civil Engineering, Polytechnic Institute of Coimbra, Portugal. CEng, MSc, PhD. E- \\ mail: ednativi@dec.uc.pt
}

\begin{abstract}
This article reviews the state-of-the-art on autonomous vehicles as of 2016, including their impact at socio-economic, energy, safety, congestion, and land-use levels. This impact study focuses on issues that are common denominator and are bound to arise independently of regional factors, such as (but not restricted to) change to vehicle ownership patterns and driver behaviour, opportunities for energy and emissions savings, potential for accident reduction and lower insurance costs, and requalification of urban areas previously assigned to parking. The challenges that lie ahead for carmakers, law and policy makers are also explored, with an emphasis on how these challenges affect the urban infrastructure and issues they create for municipal planners and decision-makers. The article concludes with a summarising SWOT analysis that integrates and relates all these aspects.
\end{abstract}

Keywords: Reviews, transport planning, town and city planning 


\section{Introduction}

The automotive industry is currently undergoing two major transformations, which will arguably shape the future of this industry and modern societies. The first of these transformations is the energy challenge, triggered by sustainability worries and environmental concerns, which calls for the industry to develop powertrains to replace the current status-quo, almost entirely dominated by the Internal Combustion Engine (ICE). The second, which is the main topic of this article, and is linked to the first, is the autonomous driving.

The last decades witnessed massive advances in computers, software, sensors and communications. This progress provided the necessary technological support for taking on the challenge of making an autonomous vehicle (AV). Sensing that such an artefact could open new markets, major technological companies, such as Google or Apple, took on the AV challenge, with car companies following closely. As of today, just about every major car manufacturer has its own AV programme.

From the business perspective, new business models appeared for the transport sector, such as car/ride-sharing services and modern on-demand, vehicle-as-a-service companies (UBER, Lyft, etc.). A combination of autonomous driving with the emerging business models may bring a new, disruptive mobility paradigm that has the potential to overcome many current and future mobility challenges.

The new mobility paradigm can significantly alter the current car ownership model, replacing possession/renting with on-demand services, which are expected to become more affordable in the future. It should integrate AVs with public transport systems and non-motorised transport modes, combining them efficiently, with business services bridging the gaps between modes.

Regardless, the mere existence and use of AVs can, as will be argued below, impact societies, the economy, cities, and the environment at many levels. Everything will, of course, depend on policy, consumer acceptance and market penetration. It is the purpose of this article to expose and discuss these impacts and, where possible, to explore further and quantify them. 


\section{State-of-the-art}

\section{Present state and levels of automation}

Fully automated driving has been pursued in a stepwise approach by carmakers, who have been developing and implementing ever-more complex driver assistance systems (DAS), in an effort to offer their customers plus-values.

As of today, many conventional cars are already equipped with multiple DAS, which assist driving and manoeuvring (e.g., cruise control, lane assistance, fatigue monitoring, park assistance, traffic signal recognition, emergency braking, evasive steering, night vision, blind spot monitor, $360^{\circ}$ cameras, traffic jam assist). See Bengler et al. (2014) for review on DAS and its goals.

Integrating the various DAS leads to a certain degree of driving autonomy, making it necessary to define automation levels. Gasser and Westhoff (2012), NHTSA (2013), and SAE International (2014) define these according to both the capabilities of the available technology and the tasks performed by the human driver (see appendix 1 for a description of SAE levels). The Society of Automobile Engineers (SAE) defines six different levels while both the USA National Highway Traffic Safety Administration (NHTSA) and the Federal Highway Research Institute (BASt) in German define only five levels (ERTRAC, 2015). The SAE distinguishes high automation (fifth level) from full automation (sixth level) since the automation level depends on the driving scenario. It should be noted that in every definition, there is a key distinction between the third and fourth level. In the third level, human driver performs part of the dynamic driving task while in the fourth level that is performed by the automated driving system.

Present day DAS are usually at the first three automation levels. Systems at upper levels are almost entirely in the development stage.

\section{Experiences on high/full automation}

Leading the pack on the quest for AVs are Google and Tesla, but there are many automakers and satellite companies in the race, some of them in cooperation (CB Insights, 2016). While high/full automation is still at a pilot stage, it is only a matter of time until the concept becomes a reality, as companies' commitment and recent examples below show:

In August 2013, the Mercedes-Benz S-Class S500 Intelligent drive completed the 'Bertha Benz memorial route' in fully autonomous mode (103 km of rural roads, small villages and major cities) (Ziegler et al., 2014).

Volvo's 'Drive Me trial' already has test AVs driving on Swedish roads and by 2017 it intends to have real-world customers using a fleet of $100 \mathrm{AVs}$ on public roads (VOLVO, 2016). 
Tesla implemented autopilot technology in October 2015 (Tesla, 2015), one of the most advanced assistance technologies, capable of replacing the driver in most situations.

On September 2016, UBER launched its first driverless fleet in Pittsburgh, USA, the first time, driverless cars are accessible to the general public (Business, 2016). Besides the customers, there are two operators in the vehicle: a trained Uber engineer and a person taking notes.

Lyft followed suit and associated with General Motors to deploy and test a fleet of self-driving Chevrolet Bolt electric taxis on public roads (WSJ, 2015b).

Many more companies are preparing their own AV testing. See e.g. driverless-future (2016) for a roadmap of these companies.

\section{Regulation}

Legislators are becoming increasingly aware that AVs call for a revision of current regulation. Accordingly, in 2014 the governments of Austria, Belgium, France and Italy submitted an amendment to the Vienna Convention on Road Traffic (ECE, 1968), which stipulates that 'every vehicle shall have a driver who shall at all times be able to control his vehicle', in order to allow for "vehicle systems which influence the way vehicles are driven and to take account of recent technical developments" (ECE, 2014). This amendment came into force on 23/March/2016 and allows for a car to drive itself if the automated driving technologies are in conformity with the United Nations vehicle regulations, or can be overridden or switched off by the driver. However, the driver must be present and be able to take control at any time. A workgroup within the United Nations Economic Commission for Europe (UNECE) is elaborating a further update to the Vienna Convention to enable the use of driverless systems in future (Mercedes-Benz, 2016).

Despite the above legal updates, at present in Europe AVs cannot be freely used on public roads because regulation regarding steering equipment only permits fully self-steering systems for speeds of up to $10 \mathrm{~km} / \mathrm{h}$ (EU (European Union), 2008). Tests have been taken under ad hoc legal permits, specific conditions and places.

Regulating AV use is but one of the legal challenges that lie ahead. As will be shown below, AVs have other implications that call for special legislation.

\section{Impacts of AVs}

Autonomous vehicles are expected to have a high impact on cities and societies. Societal changes are however slow-paced and gradual, contrasting with nowadays evolution of technology, 
which is usually a swift affair. Nevertheless, it seems clear that AVs will, at some stage and to a certain degree, make part our lives. This section discusses how they may impact that life, assuming AVs reached full automation levels.

\section{Socio-economic impact}

\section{Vehicle ownership}

This is possibly the biggest societal change AVs can bring. Currently people tend to have (or long-term rent) a car of their own, so as to benefit from ownership advantages, such as availability, flexibility, privacy, and comfort, unmatched by public transportation. Collective inefficiency is the price to pay for individual convenience, as private cars are mainly inactive during the day. They are essentially used in the peak hours (less than 1 hour per day - ITF (2015b); WSJ (2015a)), usually running with just one occupant.

On-demand services, such as the taxi, provide some of the benefits of personal vehicles, without the nuisance of ownership responsibilities. The rise of mobile devices made it possible for new business models to appear in this sector, such as UBER or car/ride-sharing services. For the latter example, it is estimated that one vehicle can replace at four to eight personal vehicles (MOMO, 2010), while Sivak and Schoettle (2015) estimate that the use of household vehicles by multiple residents could reduce vehicle ownership up to 43\% (cited by Litman (2015)). Shared AVs have the potential to reduce the cost of the current on-demand services, in many use scenarios to values below the cost of ownership, thus fostering a change on the vehicle ownership paradigm. Indeed, even nowadays is not uncommon for people to systematically opt for on-demand services in densely populated cities, when they can afford it. Because AVs fleets have no expenses with driver salaries, they can lower on-demand services prices to more affordable levels (Chen et al., 2016).

To understand how plausible this paradigm change can be, an estimation was made on how much taxi prices may come down considering a driverless fleet, based on simple assumptions and field data from a study of taxi services in Lisbon, Portugal (IMTT, 2006). Assuming that the taxi company passes $90 \%$ of driverless service savings to the customer, this results in a taxi fare reduction of roughly one-third. Considering scenarios of commuting and all-purpose use of a car (commuting plus three daily week-end trips), cost-comparison charts between three car usufruct models, namely small city car (ownership), taxi, and driverless taxi, can be derived. These are shown in Figures 1 and 2 below, as a function of commuting distance. More details on how the chart was derived can be found in Appendix 2. 


\section{(INSERT FIGURE 1 ABOUT HERE)}

\section{(INSERT FIGURE 2 ABOUT HERE)}

Figure 1 shows that short-distance commuting (up to $5 \mathrm{~km}$ ) becomes more economical if done resorting to a driverless $\mathrm{AV}$ on-demand service. If parking costs are considered, the advantage rises to commuting distances of up to $18 \mathrm{~km}$. It is only when a vehicle is used for all-purposes that ownership becomes the more economical choice, and even then only if parking costs are not considered.

The main conclusion of this analysis is thus that $\mathrm{AVs}$ extend the range of situations where using on-demand services is advantageous. These advantages will become even more obvious if ondemand service fleets opt for electric AVs, which are cheaper to run. Although this study reflects the reality of a particular city and country (Lisbon, Portugal), it is plausible that its main assumptions, and thus its conclusions, hold in more general contexts.

Whether AVs will trigger an usufruct model change is another story because week-end and vacation trips may be considered by each consumer. Also, as there is no human surveillance, driverless taxis are more prone to be vandalised, which increases running costs due to risk (Litman, 2015). Still, AVs create a context where it becomes favourable for people to change their vehicle ownership model. This is especially true for households which currently have two vehicles (the average is 2.28 in the USA (Noor, 2008)), which can keep a family car for week-end and vacations and let go their smaller, commuting vehicle.

\section{Unemployment}

Unemployment is a major problem that can arise from automation advances. AVs will threat the job of professional drivers (see e.g. CNBC (2016)) and change the required skills for workers linked to mobility systems. Taxi and other on-demand services drivers may be the first to experience this threat, as corporations already began driverless experiments. The UBER experiment in Pittsburgh is one such example. Truck drivers may come next, as the sedentary and predictable driving style makes it "a job ripe for disruption" (The Guardian, 2016a). Also, as will be discussed below, automation allows the efficient technique of platooning of heavy weight vehicles, whose fuel efficiency gains may further encourage trucking companies to go AV. Even if the more demanding task of driving on national/municipal roads is, at a first stage, better done by a human driver, it is likely these become completely expendable as time goes on.

Companies related to vehicle repair and maintenance may experience a reduction in demand for services, due to less accidents (see below). 
Automation of manual labour work leads to more value for businesses, making the country, as a whole, richer. It also allows for creation of better, qualified jobs, as the increase in job offers for AV-related work shows (KPMG, 2015). However, more education and skills upgrade will not solve problems faced by displaced workers, a general socio-economic issue which AV dissemination will aggravate, and the solution to job losses lies in economic restructuring - cited by Palvia and Vemuri (2016). Several strategies have been proposed to solve this problem (Peters, 2016).

\section{Accident reduction and insurance premiums}

About $90 \%$ of all accidents are due to human-error (Bengler et al. (2014)). AVs have the potential to drastically reduce accidents, as AV driving is not subject to distraction, bad driving behaviour, and slow human reaction times. Consequently, it is expected that AVs have lower insurance prices (The Guardian, 2016b). Insurance companies will have to face up to new challenges such as accident liability. Schroll (2015) suggests the elimination of liability for any accidents involving self-driving cars, and recommends the creation of a National Insurance Fund to pay for all damages resulting from those accidents. In addition, other risks will arise, which will need to be evaluated by these companies, such as cyber risk and system failures.

\section{Equity}

Private AVs bring mobility to people who would otherwise be unable to drive such as e.g., teenagers, elderly, people without driver's licence. Disabled people may also benefit from AVs, depending on their degree of disability. In a context of ageing population, they may contribute to solve some mobility problems of older people (EC, 2014).

\section{Energy/emissions and traffic impact}

\section{Vehicular communications and platooning}

Vehicular communications have the potential for improving traffic efficiency and consequently reducing traffic delay. They can advise other AVs and non-AV drivers in advance about traffic events, optimising their driving by reducing stop times and unnecessary accelerations/decelerations, and lead to other ways of obtaining efficiency: Luo, Xiang et al. (2016) proposed a dynamic automated lane change manoeuvre based on vehicle-to-vehicle (V2V) communication, whereas Zohdy and Rakha (2016) developed a tool that optimises the movement of vehicles equipped with cooperative adaptive cruise control in the vicinity of intersections, which can reduce average intersection delay and fuel consumption by $90 \%$ and $45 \%$, respectively. Again, the advantages of 
these technologies are strongly dependent on their penetration rates. If all vehicles were autonomous, intersections could become fully smart, with traffic flowing in an interwoven way, for almost zero delay (Tachet et al., 2016). Since this situation is not expectable in the near-future, research has been done on how to best harmonise intersection flow with incoming AVs and non-AVs (Yang and Monterola, 2016).

Vehicle-to-vehicle and vehicle-to-infrastructure (V2I) communications, whose reaction times are much shorter than human times, make platooning possible, i.e. to have vehicles riding very close to each other, reducing aerodynamic drag and consequently fuel consumption. Zabat et al. (1995) showed that fuel efficiency could improve up to $30 \%$ - cited by Alessandrini et al. (2015). In addition, close riding reduces congestion. Platooning requires however legal changes for road cruising, as nowadays it is mandatory to keep a distance to next vehicle.

The greater the market penetration of $\mathrm{AVs}$ and vehicular communications, the more effective platooning will be. Wang et al. (2015) found in simulations that both emissions and total travel delay of the platoon were reduced as market penetration of AVs increased. The same conclusion was reached by Li et al. (2015), who studied a fuel-saving strategy (Pulse-and-Glide) in a platoon with AVs and non-AVs.

\section{Electric vehicles and on-demand services}

On-demand services are also a natural stage for the massification of electric AVs (Chen et al., 2016), as these are cheaper to operate and maintain (Egbue and Long, 2012), have zero emissions (important in an urban environment), and automatically look for a charging station when low on battery. If the above-argued rise in vehicle-as-a-service use becomes a reality, it will have as byproduct a speed up of vehicle fleet replacement, thereby facilitating the introduction of new, more fuel-efficient vehicles and technologies. More on-demand services usage also translates to less fuel used in seeking for a parking place, an activity which can represent $40 \%$ of fuel use in congested urban areas (Mitchell, 2007).

\section{Smaller and lighter vehicles}

OECD average car occupancy rate is about 1.5 (ITF, 2015a). Since AVs have a permanently vacant seat, vehicle-as-a-service companies are likely to invest on fleets of smaller, lighter two-seater cars, which are more efficient than general purpose vehicles with respect to costs, energy and space.

Built-in safety and crash resistance features is one of the reasons conventional vehicles get heavy. As automation increases, AVs became safer and consequently some of these features can be 
removed, reducing fuel consumption and emissions. According to MacKenzie et al. (2014), safety features contributed $112 \mathrm{~kg}$ out of $1452 \mathrm{~kg}(7.7 \%)$ of the average new USA car's weight in 2011. The removal of safety weights would decrease fuel consumption by $5.5 \%$ - cited by Wadud et al. (2016).

\section{Automated eco-driving}

Eco-driving is a driving pattern which avoids high speeds and sharp accelerations/breaking. It can reduce fuel consumption and emissions by $5-20 \%$ (Barth and Boriboonsomsin, 2009) and improve safety. Eco-driving patterns can be programmed into AV control systems, which additionally can operate them more efficiently than human drivers.

\section{Traffic congestion and transport infrastructure}

Since AVs can provide mobility for more people, travel demand may increase. Sivak and Schoettle (2015) estimate this increase to go as high as $11 \%$. The potential of AVs to reduce travel costs and travel time may also induce people to make more, and/or longer, trips - Jevon's Paradox (Norton, 2015). However, more travel demand does not necessary implies more vehicles on the road. Dynamic ride sharing schemes can be used to collect unable driving people in the same neighbourhood and working/undertakings (leisure activities) in the same place (Fagnant and Kockelman, 2015). This increase in demand will depend on the new mobility pattern/vehicle ownership pattern.

This demand increase can, to some extent, be accommodated by the infrastructure because AVs are more traffic-efficient, due to platooning and vehicle communication. In the same spirit, price decrease of on-demand services can make these more attractive as a hub transport mode between public transport modes, which are more space-efficient, further reducing congestion.

It is therefore not clear whether AVs can ultimately lead to more or less traffic congestion. The land-use discussion below brings even more uncertainty to this issue.

\section{Land-use}

Mobility and land-use have been inherently intertwined. There has been much speculation concerning the land-use impacts of AVs (Heinrichs (2016); Alessandrini et al. (2015); Bajpai (2016)), as it may trigger multiple effects. For example, a reduction in vehicle ownership will arguably decrease parking requirements, while a reduction of travel costs and travel times might induce more urban sprawling. 


\section{Parking}

Currently cars are used only for short periods of time. Most of the time, they stay parked (WSJ, 2015a). Finding a parking spot may, in addition to fuel waste, increase traffic up to $15 \%$ (Alessandrini et al., 2015). Fully AVs can mitigate these problems since they can drive passengers to their destination, and then drive home or to a parking area further away. It is however not clear whether society will accept empty AVs squandering fuel and polluting while looking for parking far away. On-demand services or shared AVs are more efficient in this respect, as they do not need parking.

Nevertheless, AVs do have potential for saving parking space, not only by increasing the use of on-demand services, but also by reducing space required for self-parking, should it be necessary. According to Safdie (1998), compact storage of AVs in specialized depots requires only one quarter of the space currently required in a conventional parking (cited by Alessandrini et al. (2015)).

\section{Urban environment}

The increase of urban sprawl that lower travel costs/time may induce can be partly compensated by judiciously relocating space freed up from the decrease in parking needs. If this extra space from e.g., supressing a parking lane, is used to construct quality bikepaths, an increase in bicycle use can be expected (Cervero et al., 2013), decongesting the streets and possibly contributing to break the vicious cycle of automobile use (UN, 2012) and bring people to the city centres. An architectural study on possible street configuration changes for the city of San Francisco, USA, was presented in (Tierney, 2014). One of the examples given in that study featured a $100 \mathrm{ft}$ wide street with eight lanes converted into a four-lane street with bike lanes and double the green space.

Political decision making is crucial here: if freed-up space is not used to foster active travel modes or public transportation, it may be used for something else that goes in the opposite direction.

\section{Risks and Challenges}

Although the potential benefits of AVs are likely to be substantial, their use will pose several risks and challenges. The adoption of AVs will greatly depend on the way in which those risks and challenges are managed. It will not be an easy task since technologies have been evolving faster than the regulators can keep up. 


\section{Technological barriers/developments}

Prior to massification, AVs need to be able to operate competently in the heavily constrained 2D environment that is traffic, especially urban traffic. Reaching navigation proficiency in this environment is much more complex than in the case of airplanes, which is the main reason auto-pilot appeared for airplanes much sooner than for cars.

AVs use various sensors systems and digital maps to scan their nearby environment. All information is combined in an on-board computer system that uses sophisticated algorithms to determine if the vehicle can move to a new position, in a continuous process which makes decisions many times per second. This navigation system must be reliable in all weather conditions and environments for that, there is still a lot of work to do.

Vehicle map position must precise and reliable in real-time, as well as environment information. Some situations have proved very challenging, mainly because technology is based on optical systems. For example: hidden lane markings, night-time, bad weather conditions, bridges, blinding light from the sun, obscured lights, unusual signage, four-way junctions, hand gestures, head nods and hand gestures, blocked GPS signal, etc. In addition AVs will need to be able to recognize and deal appropriately with unforeseen situations.

Overcoming these situations reliably requires improving maps, sensors and computer algorithms. Deep learning systems (TechCrunch, 2016) may help dealing with unpredictable environments, as they can pass human-like decision making patterns to vehicles. This requires however a long learning period, which may delay time-to-market. Instead, some improvements can also be made to fix the infrastructure in order to be as predictable as possible (WIRED, 2016).

In the quest for high-precision maps and GPS data, which are essential for AVs, the Japanese government and the European Union plan integration of their GPS satellite constellations (NIKKEY Asian Review, 2016). An alternative to GPS (or complement to it) was developed a team of USA researchers, exploiting existing environmental signals such as cellular and Wi-Fi (TECH i.e., 2016). Detailed street-level maps of cities using vector-based graphics have also been developed (Road Show, 2016). With this technology, AVs determine their position by calculating their distance to known objects, instead of using GPS.

Other technological developments include: software for vehicle guidance without GPS by Oxbotica (Popular Science, 2016); a localizing ground-penetrating radar (LGPR) that works well in all weather conditions, day and night, developed by the MIT Lincoln Laboratory (MIT News, 2016); LIDAR technology, which allows AVs drive in the dark as in daylight (Fortune, 2016) (electrek@, 2016). This technology has become increasingly cheaper and smaller (Autoevolution, 2016). 


\section{Challenges for municipalities}

As recognized by Fox (2016), "Currently, little planning is being done to prepare for driverless technology". But municipal decision-makers will soon be prompted to plan the city for AVs. They will face both technical decisions (e.g., transport infrastructure issues) and political ones (e.g., landuse policies), whose outcome may either favour a smooth AV transition or complicate matters. A breakdown of possible issues that municipalities may encounter can be found in (Guerra, 2015).

\section{Legal, liability and ethical issues}

Along with regulatory legislation on how AVs are to be used, the Highway Code and certification standards will need to be revised. The Gear 2030 (EC, 2016) presents a review of the EU legislation related with $\mathrm{AVs}$, with special attention to the challenges that such vehicles will pose.

Of particular importance is liability in accident cases. If an accident occurs, who is liable? The car's owner, or the automaker? Some automakers (Mercedes, Volvo and Goggle) said they will accept responsibility and liability if their technology is at fault once it becomes commercially available (Jalopnik, 2015). Hevelke and Nida-Rümelin (2015) present a discussion about who should be held responsible for accidents of fully AVs from a moral stand point. According to them, automakers responsibility should be limited to not obstruct AVs improvements.

As to ethical problems, these may arise before imminent crashing, with algorithm behaviour having to decide which humans to endanger (Goodall, 2014).

\section{Cybersecurity and data privacy}

Like with all electronical devices, AV cybersecurity is a serious issue. In 2015 two hackers remotely took control of a Jeep Cherokee (WIRED, 2015) and this year a team of hackers did the same for a Tesla Model S (The Guardian, 2016c), raising fears that a large-scale attack could bring a city to a halt. As result, some carmakers and service companies resorted to crowdsourcing, rewarding hackers who find bugs in theirs software. A set of automotive cybersecurity best practices was also published (AUTO-ISAC, 2016).

AVs collect massive amounts of data as they operate, data which can be "foodstock" for business opportunities (Financial Post, 2016). Associated to this are data privacy and security issues. Authorities are becoming aware of these issues and draft regulations are starting to appear (DMV, 2015). 


\section{SWOT analysis}

The SWOT table below summarises the discussion of previous sections. It is presented from a general, holistic perspective, not specifically a business-oriented one. One of its key features is that congestion and traffic demand could be interchanged, depending on the political choices made by municipal decision-makers.

\section{(INSERT TABLE 1 ABOUT HERE)}

\section{Conclusions and future}

The usually hard task of anticipating the future becomes even harder when a large change, such as the appearance of autonomous vehicles, is looming. Many consequences of their appearance are, at best, nebulous at the present stage, along with how deep they might reach. What seems to be consensual is the fact that AVs will bring, sooner or later, a paradigm change in transport. Whether this change will come from widespread adhesion to new car usufruct models, traffic efficiency, electric powering, other factors or any combination of former is not clear. Neither is what practical implications it will have on cities, especially if one considers that cities change due to many factors.

This research summarised the possible impacts of AVs and the state-of-the-art with respect to academic research on the subject. It also argued that AVs can make alternative car usufruct models more affordable, possibly to an extent large enough that these can subsequently shape the city and traffic. However, technological hurdles must be surpassed before any of these come to fruition. Recent Tesla auto-pilot crashes prove even the more basic AV functions need vital upgrades, leaving harnessing of all AV potential still far away.

An AV-based society requires a different collective mind-set. People will need time to adapt, and it is likely that some die-hards will never give-up being at the helm. Nevertheless, with big companies so committed to AV development, it is only a matter of time before some of the aforementioned impacts unveil. Some forecasts as to what the future may bring can be found in the recent work of (Litman, 2015).

With research on AVs impacts still at its infancy, the field is ripe for exploring and modelling them in a quantitative way, anticipating their extent and side effects. Research on usufruct model changes, traffic demand and congestion, and how to best integrate AV with normal traffic rank on top of this to-do list, given their potential to shape the city and its urban way of life. Extending the study presented in this article in section 3 to more cities and countries may help estimate short- to mid-term regional penetration rates. 


\section{Acknowledgements}

This work was partially supported by the Portuguese Foundation for Science and Technology under grant PEst-OE/EEI/UI308/2014.

\section{References}

Alessandrini A, Campagna A, Site PD, Filippi F and Persia L (2015) Automated Vehicles and the Rethinking of Mobility and Cities. Transportation Research Procedia, 5: 145-160, http://dx.doi.org/10.1016/j.trpro.2015.01.002.

AUTO-ISAC (2016) Automotive Cybersecurity Best Practices - Executive Summary. AUTO-ISAC, Automotive Information Sgaring and Analysis Center. See https://www.automotiveisac.com/assets/img/executive-summary.pdf (accessed 30/07/2016).

Autoevolution (2016) Tesla's Decision to Snub LIDAR Might Come Back and Bite It One Day. See http://www.autoevolution.com/news/tesla-s-decision-to-snub-lidar-might-come-back-andbite-it-one-day-111598.html (accessed 29/10/2016).

Bajpai JN (2016) Emerging vehicle technologies \& the search for urban mobility solutions. Urban, Planning and Transport Research, 4 (1): 83-100, http://dx.doi.org/10.1080/21650020.2016.1185964.

Barth M and Boriboonsomsin K (2009) Energy and emissions impacts of a freeway-based dynamic eco-driving system. Transportation Research Part D: Transport and Environment, 14 (6): 400-410, http://dx.doi.org/10.1016/j.trd.2009.01.004.

Bengler K, Dietmayer K, Farber B et al. (2014) Three Decades of Driver Assistance Systems: Review and Future Perspectives. IEEE Intelligent Transportation Systems Magazine, 6 (4): 622, http://dx.doi.org/10.1109/MITS.2014.2336271.

Business (2016) Uber launches driverless car service in Pittsburgh. See https://www.thestar.com/business/2016/09/14/uber-trials-driverless-cars-in-pittsburgh.html (accessed 15/09/2016).

CB Insights (2016) 33 Corporations Working On Autonomous Vehicles. See https://www.cbinsights.com/blog/autonomous-driverless-vehicles-corporations-list/ (accessed 15/09/2016).

Cervero R, Caldwell B and Cuellar J (2013) Bike-and-Ride: Build It and They Will Come. Journal of Public Transportation, 16 (4), http://dx.doi.org/10.5038/2375-0901.16.4.5.

Chen TD, Kockelman KM and Hanna JP (2016) Operations of a Shared, Autonomous Electric Vehicle Fleet: Implications of Vehicle \& Charging Infrastructure Decisions. Transportation Research Board 95th Annual Meeting, Washington DC, United States.

CNBC (2016) Driverless cars will kill the most jobs in select US states. See http://www.cnbc.com/2016/09/02/driverless-cars-will-kill-the-most-jobs-in-select-usstates.html (accessed 29/10/2016). 
DMV (2015) DMV Releases Draft Requirements for Public Deployment of Autonomous Vehicles State Seeks Public Comment on Draft Document. See https://www.dmv.ca.gov/portal/dmv/detail/pubs/newsrel/newsrel15/2015 63 $\quad$ (accessed 29/10/2016).

driverless-future (2016) Driverless car market watch - Autonomous car forecasts. See http://www.driverless-future.com/?page id=384 (accessed 29/10/2016).

EC (2014) Population ageing in Europe Facts, implications and policies. See https://ec.europa.eu/research/social-sciences/pdf/policy_reviews/kina26426enc.pdf.

EC (2016). Gear 2030 Discussion Paper - Roadmap on highly automated vehicles. European Commission.

ECE (1968). Convention on Road Traffic, Done at Vienna. Economic Commission for Europe.

ECE (2014). Consistency between the Convention on Road Traffic (1949) and Vehicle Technical Regulations United Nations, Economic and Social Council, Economic Commission for Europe, ECE/TRANS/WP.1/2014/4.

Egbue O and Long S (2012) Barriers to widespread adoption of electric vehicles: An analysis of consumer attitudes and perceptions. Energy Policy, 48: 717-729, http://dx.doi.org/10.1016/j.enpol.2012.06.009.

ERTRAC (2015) Automated Driving Roadmap. ERTRAC Task Force "Connectivity and Automated Driving", The European Road Transport Research Advisory Council. See http://www.ertrac.org/uploads/documentsearch/id38/ERTRAC_Automated-Driving-2015.pdf (accessed 15/09/2016).

EU (European Union) (2008) Regulation No 79 of the Economic Commission for Europe of the United Nations (UN/ECE) - Uniform provisions concerning the approval of vehicles with regard to steering equipment. Official Journal of the European Union.

Fagnant DJ and Kockelman KM (2015) Dynamic Ride-Sharing and Optimal Fleet Sizing for a System of Shared Autonomous Vehicles. TRB 94th Annual Meeting Compendium of Papers.

Financial Post (2016) The real prize and threat of the driverless car revolution is data: 'The car knows a lot about you'. See http://business.financialpost.com/fp-tech-desk/the-real-prize-andthreat-of-the-driverless-car-revolution-is-data-the-car-knows-a-lot-about-you (accessed 29/10/2016).

Fortune (2016) What Happened When Ford Tested Its Self-Driving Car in Total Darkness. See http://fortune.com/2016/04/11/ford-self-driving-car-dark/ (accessed 29/10/2016).

Fox SJ (2016) Planning for Density in a Driverless World. Northeastern University Law Journal, Forthcoming, February 19, http://dx.doi.org/10.2139/ssrn.2735148

Gasser TM and Westhoff D. 2012. BASt-study: Definitions of automation and legal issues in Germany. Presentation at the 2012 Road Vehicle Automation Workshop, Irvine, CA. See http://onlinepubs.trb.org/onlinepubs/conferences/2012/Automation/presentations/Gasser.pdf [Accessed 05/07/2016]. 
Goodall N (2014) Ethical Decision Making During Automated Vehicle Crashes. Transportation Research Record Journal of the Transportation Research Board 2424: 58-65, http://dx.doi.org/10.3141/2424-07.

Guerra E (2015) Planning for Cars That Drive Themselves: Metropolitan Planning Organizations, Regional Transportation Plans, and Autonomous Vehicles. Journal of Planning Education and Research, 1 (15), http://dx.doi.org/ 10.1177/0739456X15613591

Heinrichs D (2016). Autonomous Driving and Urban Land Use. In Autonomous Driving: Technical, Legal and Social Aspects. Berlin, Heidelberg: Springer Berlin Heidelberg. pp. 213-231.

Hevelke A and Nida-Rümelin J (2015) Responsibility for Crashes of Autonomous Vehicles: An Ethical Analysis. Science and Engineering Ethics, 21 (3): 619-630, http://dx.doi.org/10.1007/s11948-014-9565-5.

IMTT (2006) Estudo Sobre as Condições de Exploração de Transportes em Táxi na Cidade de Lisboa. Instituto da Mobilidade e dos Transportes Terrestres, I. P. See http://www.imtt.pt/sites/IMTT/Portugues/BibliotecaeArquivo/RepertorioIMTTanteriora2008/ EstudoseRelatorios/Documents/IMTT TaxisEstudo2006.pdf (In Portuguese) (accessed $30 / 09 / 2016)$.

ITF (2015a) A New Paradigm for Urban Mobility - How Fleets of Shared Vehicles Can End the Car Dependency of Cities International Transport Forum (OECD). See http://www.itfoecd.org/sites/default/files/docs/cop-pdf-03.pdf (accessed 29/10/2016).

ITF (2015b) Urban Mobility System Upgrade, How shared self-driving cars could change city traffic. International Transport Forum (OECD). See http://www.itfoecd.org/sites/default/files/docs/15cpb_self-drivingcars.pdf (accessed 05/07/2016).

Jalopnik (2015) Mercedes, Google, Volvo To Accept Liability When Their Autonomous Cars Screw Up. See http://jalopnik.com/mercedes-google-volvo-to-accept-liability-when-their$\underline{1735170893}$ (accessed 22/09/2016).

KPMG (2015) Connected and Autonomous Vehicles - The UK Opportunity. See https://www.kpmg.com/BR/en/Estudos Analises/artigosepublicacoes/Documents/Industrias/ Connected-Autonomous-Vehicles-Study.pdf (accessed 15/09/2016).

Li SE, Deng K, Zheng Y and Peng H (2015) Effect of Pulse-and-Glide Strategy on Traffic Flow for a Platoon of Mixed Automated and Manually Driven Vehicles. Computer-Aided Civil and Infrastructure Engineering, 30 (11): 892-905, http://dx.doi.org/10.1111/mice.12168.

Litman T (2015) Autonomous Vehicle Implementation Predictions - Implications for Transport Planning. Transportation Research Board 94th Annual Meeting, Washington DC, United States.

Mercedes-Benz (2016) Autonomous driving: the legal framework. See https://www.mercedesbenz.com/en/mercedes-benz/next/automation/autonomous-driving-the-legal-framework/ (accessed 13/09/2016). 
MIT News (2016) Pinpointing vehicles with high precision under adverse weather conditions. See http://news.mit.edu/2016/pinpointing-vehicles-with-high-precision-under-adverse-weatherconditions-0623 (accessed 29/10/2016).

Mitchell WJ. 2007. SMART CITIES MIT Media Lab: Concept Car Project. See http://h20.media.mit.edu/pdfs/wjm2007-0509.pdf [Accessed 29/10/2016].

MOMO (2010) The State of European Car-Sharing - Final Report D 2.4 Work Package 2 momo Car-Sharing - More options for energy efficient mobility through Car-Sharing. See http://www.eltis.org/sites/eltis/files/tool/the state of carsharing_europe.pdf $\quad$ (accessed $22 / 10 / 2016)$.

NHTSA (2013) Preliminary Statement of Policy Concerning Automated Vehicles. National Highway Traffic Safety Administration. See http://orfe.princeton.edu/ alaink/SmartDrivingCars/Automated_Vehicles_Policy.pdf (accessed 29/10/2016).

NIKKEY Asian Review (2016) EU and Japan connect GPS systems to boost driverless cars. See http://asia.nikkei.com/Tech-Science/Tech/In-driverless-car-push-Japan-and-EU-to-connectGPS-systems (accessed 02/11/2016).

Noor M (2008) Many Families Limiting Themselves to a Single Car. The New York Times. See http://www.nytimes.com/2008/07/27/nyregion/nyregionspecial2/27Ronecar.html (accessed 29/10/2016).

Norton P (2015). Going Faster in the Wrong Direction? History's Lessons for the Future of Roads and Streets. In Transportation Research Circular Number E-C201: Linking the Past to the Future, Lessons from History About Emerging Technology. pp. 5-9.

Palvia S and Vemuri V (2016) Forecasts of jobless growth: Facts and myths. Journal of Information Technology Case and Application Research, 18 (1): 4-10, http://dx.doi.org/10.1080/15228053.2016.1145621.

Peters MA (2016) Technological unemployment: Educating for the fourth industrial revolution. Educational Philosophy and Theory: 1-6, http://dx.doi.org/10.1080/00131857.2016.1177412.

Popular Science (2016) Oxbotica's Software for Self-Driving Cars doesn't need Gps Signal Navigates Underground and In Tunnels using a 3D Point Cloud. See http://www.popsci.com/software-for-self-driving-cars-without-gps (accessed 12/10/2016).

Road Show (2016) Forget GPS, Civil Maps gives self-driving cars street smarts. See https://www.cnet.com/roadshow/news/forget-gps-civil-maps-gives-self-driving-cars-streetlevel-positioning/ (accessed 15/10/2016).

SAE International (2014) Taxonomy and Definitions for Terms Related to On-Road Motor Vehicle Automated Driving Systems. J3016_201401.

Schroll C (2015) Splitting the Bill: Creating a National Car Insurance Fund to Pay for Accidents in Autonomous Vehicles. Northwestern University Law Review, 109 (3). 
Sivak M and Schoettle B (2015) Influence of Current Nondrivers on the Amount of Travel and Trip Patterns with Self-Driving Vehicles. The University of Michigan Transportation Research Institute. UMTRI-2015-39. See http://www.umich.edu/ umtriswt/PDF/UMTRI-201539 Abstract_English.pdf (accessed 12/10/2016).

Tachet R, Santi P, Sobolevsky S et al. (2016) Revisiting Street Intersections Using Slot-Based Systems. PLoS ONE, 11 (3), http://dx.doi.org/10.1371/journal.pone.0149607.

TECH i.e. (2016) Cellular signals-based navigation for driverless cars soon. See http://indianexpress.com/article/technology/tech-news-technology/cellular-signals-basednavigation-for-driverless-cars-soon-3082562/ (accessed 17/10/2016).

TechCrunch (2016) Drive.ai uses deep learning to teach self-driving cars - and to give them a voice. See https://techcrunch.com/2016/08/30/drive-ai-uses-deep-learning-to-teach-self-drivingcars-and-to-give-them-a-voice/ (accessed 12/10/2016).

Tesla (2015) Your Autopilot has arrived. See https://www.tesla.com/blog/your-autopilot-has-arrived (accessed 15/09/2016).

The Guardian (2016a) Self-driving trucks: what's the future for America's 3.5 million truckers? . See https://www.theguardian.com/technology/2016/jun/17/self-driving-trucks-impact-on-driversjobs-us (accessed 12/09/2016).

The Guardian (2016b) Smart cars: how technology is putting the brakes on insurance premiums. See https:/www.theguardian.com/money/2016/may/16/smart-technology-cars-insurancepremiums-safer-cheaper (accessed 14/09/2016).

The Guardian (2016c) Team of hackers take remote control of Tesla Model S from 12 miles away. See https://www.theguardian.com/technology/2016/sep/20/tesla-model-s-chinese-hackremote-control-brakes (accessed 14/10/2016).

Tierney G (2014) Designing for the Driverless City - Reclaiming the Urban Realm, SPUR San Francisco. $\quad$ See http://www.spur.org/sites/default/files/events pdfs/SPUR Desinging4DriverlessEtc finalP+ Wrev1A.pdf (accessed 29/11/2016).

UN (2012) Shanghai Manual: A Guide for Sustainable Urban Development in the 21st Century Chapter 4, 2012, United Nations Department of Economic and Social Affairs (UNDESA). See https://sustainabledevelopment.un.org/index.php?page=view\&type $=400 \& n r=633 \&$ menu $=35$ (accessed 29/11/2016).

VOLVO

Intellisafe, autopilot. See http://www.volvocars.com/au/about/innovations/intellisafe/autopilot (accessed 25/08/2016).

Wadud Z, MacKenzie D and Leiby P (2016) Help or hindrance? The travel, energy and carbon impacts of highly automated vehicles. Transportation Research Part A: Policy and Practice, 86: 1-18, http://dx.doi.org/10.1016/j.tra.2015.12.001. 
Wang Z, Chen X, Ouyang Y and Li M (2015) Emission Mitigation via Longitudinal Control of Intelligent Vehicles in a Congested Platoon. Computer-Aided Civil and Infrastructure Engineering, 30: 490-506, http://dx.doi.org/10.1111/mice.12130.

WIRED (2015) Hackers Remotely Kill a Jeep on the Highway-With Me in It. See https:/www.wired.com/2015/07/hackers-remotely-kill-jeep-highway/ (accessed 14/10/2016).

WIRED (2016) Self-Driving Cars Won't Work Until We Change Our Roads-And Attitudes. See https:/www.wired.com/2016/03/self-driving-cars-wont-work-change-roads-attitudes/ (accessed 10/10/2016).

WSJ (2015a) Could Self-Driving Cars Spell the End of Ownership? When companies like Apple and Tesla roll out their autonomous vehicles, the need for a personal car might be a thing of the past. The Wall Street Journal. See http://www.wsj.com/articles/could-self-driving-cars-spellthe-end-of-ownership-1448986572 (accessed 25/09/2016).

WSJ (2015b) GM, Lyft to Test Self-Driving Electric Taxis. See http://www.wsj.com/articles/gmlyft-to-test-self-driving-electric-taxis-1462460094.

Yang B and Monterola C (2016) Efficient intersection control for minimally guided vehicles: A selforganised and decentralised approach. Transportation Research Part C: Emerging Technologies, 72: 283-305, http://dx.doi.org/10.1016/j.trc.2016.10.004.

Ziegler J, Bender P, Schreiber M et al. (2014) Making Bertha Drive - An Autonomous Journey on a Historic Route. IEEE Intelligent Transportation Systems Magazine, 6 (2): 8-20, http://dx.doi.org/10.1109/MITS.2014.2306552.

Zohdy IH and Rakha HA (2016) Intersection Management via Vehicle Connectivity: The Intersection Cooperative Adaptive Cruise Control System Concept. Journal of Intelligent Transportation Systems, 20 (1): 17-32, http://dx.doi.org/10.1080/15472450.2014.889918. 


\section{APPENDIX 1}

\begin{tabular}{|c|c|c|c|c|c|c|}
\hline $\begin{array}{l}\text { SAE } \\
\text { level }\end{array}$ & Name & Narrative Definition & $\begin{array}{l}\text { Execution of } \\
\text { Steering and } \\
\text { Acceleration/ } \\
\text { Deceleration }\end{array}$ & $\begin{array}{l}\text { Monitoring } \\
\text { of Driving } \\
\text { Environment }\end{array}$ & $\begin{array}{l}\text { Fallback } \\
\text { Performance } \\
\text { of Dynamic } \\
\text { Driving Task }\end{array}$ & $\begin{array}{l}\text { System } \\
\text { Capability } \\
\text { (Driving } \\
\text { Modes) }\end{array}$ \\
\hline \multicolumn{7}{|c|}{ Human driver monitors the driving environment } \\
\hline $\mathbf{0}$ & $\begin{array}{c}\text { No } \\
\text { Automation }\end{array}$ & $\begin{array}{l}\text { the full-time performance by the human driver of all } \\
\text { aspects of the dynamic driving task, even when enhanced } \\
\text { by warning or intervention systems }\end{array}$ & Human driver & Human driver & Human driver & $\mathrm{n} / \mathrm{a}$ \\
\hline 1 & $\begin{array}{c}\text { Driver } \\
\text { Assistance }\end{array}$ & $\begin{array}{l}\text { the driving mode-specific execution by a driver assistance } \\
\text { system of either steering or acceleration/deceleration using } \\
\text { information about the driving environment and with the } \\
\text { expectation that the human driver perform all remaining } \\
\text { aspects of the dynamic driving task }\end{array}$ & $\begin{array}{l}\text { Human driver } \\
\text { and system }\end{array}$ & Human driver & Human driver & $\begin{array}{l}\text { Some driving } \\
\text { modes }\end{array}$ \\
\hline 2 & $\begin{array}{l}\text { Partial } \\
\text { Automation }\end{array}$ & $\begin{array}{l}\text { the driving mode-specific execution by one or more driver } \\
\text { assistance systems of both steering and acceleration/ } \\
\text { deceleration using information about the driving } \\
\text { environment and with the expectation that the human } \\
\text { driver perform all remaining aspects of the dynamic } \\
\text { driving task }\end{array}$ & System & Human driver & Human driver & $\begin{array}{l}\text { Some driving } \\
\text { modes }\end{array}$ \\
\hline \multicolumn{7}{|c|}{ Automated driving system ("system") monitors the driving environmen } \\
\hline 3 & $\begin{array}{l}\text { Conditional } \\
\text { Automation }\end{array}$ & $\begin{array}{l}\text { the driving mode-specific performance by an automated } \\
\text { driving system of all aspects of the dynamic driving task } \\
\text { with the expectation that the human driver will respond } \\
\text { appropriately to a request to intervene }\end{array}$ & System & System & Human driver & $\begin{array}{l}\text { Some driving } \\
\text { modes }\end{array}$ \\
\hline 4 & $\begin{array}{c}\text { High } \\
\text { Automation }\end{array}$ & $\begin{array}{l}\text { the driving mode-specific performance by an automated } \\
\text { driving system of all aspects of the dynamic driving task, } \\
\text { even if a human driver does not respond appropriately to a } \\
\text { request to intervene }\end{array}$ & System & System & System & $\begin{array}{l}\text { Some driving } \\
\text { modes }\end{array}$ \\
\hline 5 & $\begin{array}{c}\text { Full } \\
\text { Automation }\end{array}$ & $\begin{array}{l}\text { the full-time performance by an automated driving system } \\
\text { of all aspects of the dynamic driving task under all } \\
\text { roadway and environmental conditions that can be } \\
\text { managed by a human driver }\end{array}$ & System & System & System & $\begin{array}{l}\text { All driving } \\
\text { modes }\end{array}$ \\
\hline
\end{tabular}

Source: SAE International (2014) 


\section{APPENDIX 2}

This appendix discusses the assumptions made for the usufruct model study. For the three different car usufruct models, small city car (ownership), taxi, and driverless taxi, these assumptions were made as follows.

First, taxi company income and expenses were taken from the IMTT taxi study for the city of Lisbon, Portugal (IMTT, 2006). Driver salary was removed from the expenses and depreciation was increased to that for a vehicle costing an excess 10000 EUR over a regular one (extra cost of driverless capabilities (Litman, 2015). Considering other variables as constant, e.g., service frequency; average service kilometres; occupancy percentage; day/night service percentages (respectively $65 \% / 35 \%$ ); fuel costs, it was calculated that a decrease of $32 \%$ on taxi fares was possible, assuming that the taxi company would want an increase of $10 \%$ on its profit margin.

Second, based on taxi fares for regular taxis and driverless taxis, yearly commuting costs were evaluated as function of commuting distance for both taxi types, assuming five days/week of commuting (two trips/day). For the all-purpose case, along with commuting, six week-end trips were also considered (three each week-end day). This resulted in the dashed lines of figures 1 and 2. Note that Portuguese week-end taxi fares are more expensive than week-days fares, which is why taxis are more advantageous for commuting only.

Finally, to evaluate ownership costs, it was assumed commuting would be carried out on a small city car (12 000 EUR cost), considering 7 litres/100 km consumption, 2016 gasoline costs, 200 EUR insurance costs, 100 EUR circulation tax, and yearly linear depreciation for 10 year vehicle life cycle with $10 \%$ buyback value. This resulted in the dark solid lines of figures 1 and 2 . The grey solid lines on these figures show ownership costs if a flat rate of $150 \mathrm{EUR} / \mathrm{month}$ is added for parking expenses (average monthly parking cost in Lisbon). 
Figure_1 10000

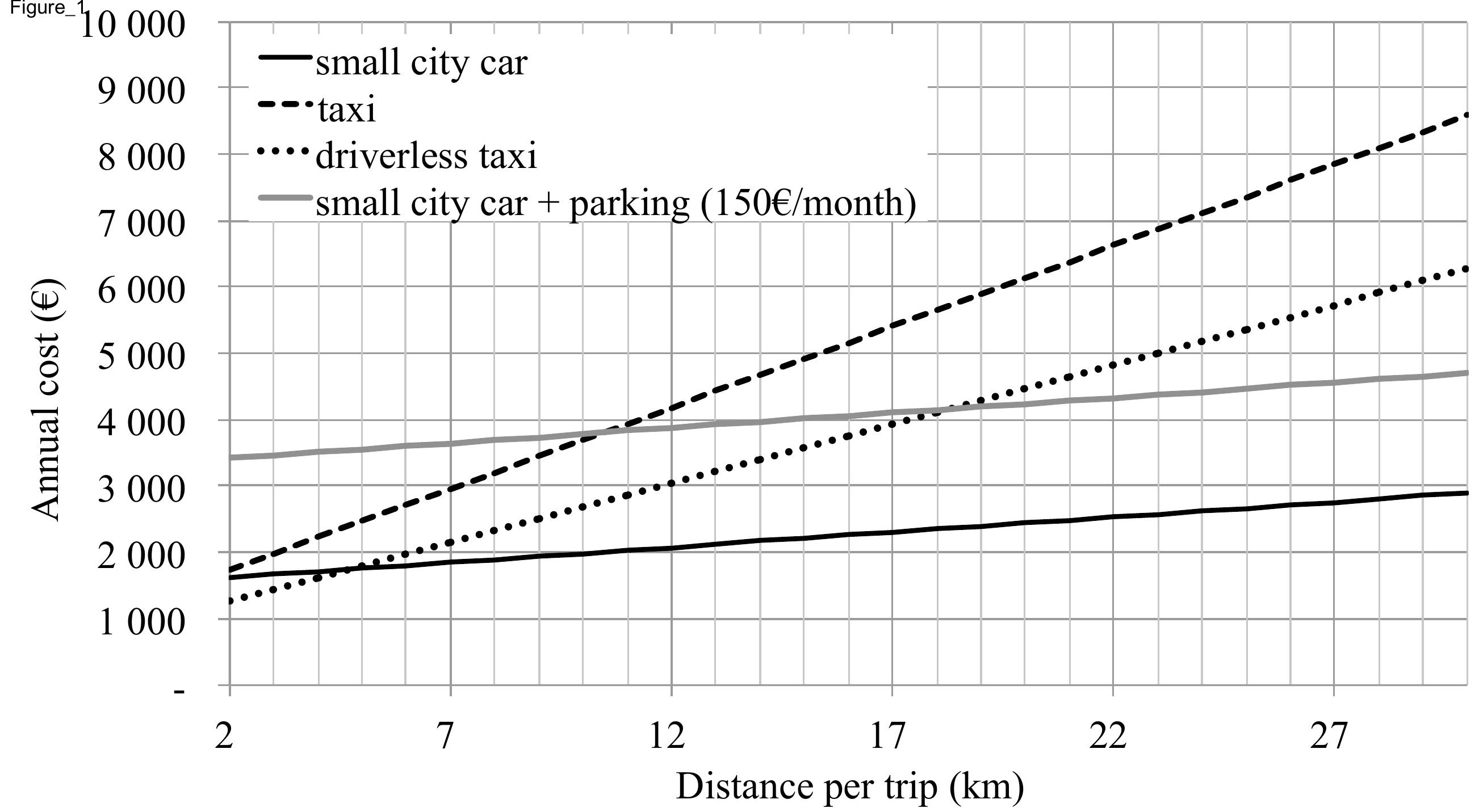




\section{N T E R N A L}

\section{TRENGTHS}

Accident reduction

Cheaper insurance policies

Equity (mobility for all)

P Increased traffic efficiency

Increased on-demand services

- Reduced travel costs

S Reduced parking demand

$\mathbf{S}$

1

$\mathbf{T}$

I

V Use of smaller vehicles

Fosters use of electric vehicles

E Requalification of parking space

Congestion reduction

Emissions reduction

\section{EAKNESSES}

Lack of regulation/certification

Reliance on technology

Costly technology

Technological issues to be solved

Legal \& liability issues

$\mathbf{N}$

Ethical issues

E

G

A

HREATS

Unemployment

Urban expansion

Increased traffic demand

Data privacy

Data security 